University of Nebraska - Lincoln

DigitalCommons@University of Nebraska - Lincoln

Faculty Publications, Department of Psychology

Psychology, Department of

September 2003

\title{
Adolescent religiosity and sexuality: an investigation of reciprocal influences
}

Sam A. Hardy

University of Nebraska-Lincoln, samhardy_unl@yahoo.com

Marcela Raffaelli

University of Nebraska-Lincoln, mraffaelli1@unl.edu

Follow this and additional works at: https://digitalcommons.unl.edu/psychfacpub

Part of the Psychiatry and Psychology Commons

Hardy, Sam A. and Raffaelli, Marcela, "Adolescent religiosity and sexuality: an investigation of reciprocal influences" (2003). Faculty Publications, Department of Psychology. 97.

https://digitalcommons.unl.edu/psychfacpub/97

This Article is brought to you for free and open access by the Psychology, Department of at DigitalCommons@University of Nebraska - Lincoln. It has been accepted for inclusion in Faculty Publications, Department of Psychology by an authorized administrator of DigitalCommons@University of Nebraska - Lincoln. 
Published in Journal of Adolescence 26 (2003), pp. 731-739. Copyright (C) 2003 The Association for Professionals in Services for Adolescents. Published by Elsevier Ltd. Used by permission. DOI:10.1016/j.adolescence.2003.09.003 Online (a) http://www.elsevier.com/locate/jado

\title{
Adolescent religiosity and sexuality: an investigation of reciprocal influences
}

\author{
Sam A. Hardy, \\ Department of Psychology, University of Nebraska-Lincoln, 238 Burnett Hall, Lincoln, NE 68588-0308, USA. \\ Corresponding author: E-mail samhardy_unl@yahoo.com \\ Marcela Raffaelli, \\ Department of Psychology, Institute for Ethnic Studies, University of Nebraska-Lincoln, \\ 238 Burnett Hall, Lincoln, NE 68588-0308, USA
}

Received and accepted September 2003

\begin{abstract}
The present study examined potential bi-directional associations between religiosity and first sexual intercourse. The sample, drawn from the National Longitudinal Survey of Youth, included 303 teens (22\% Hispanic, 35\% Black, 43\% White; 53\% male) aged 15-16 in 1996 and 1718 in 1998. All teens included in the sample were virgins at Time 1. In the longitudinal analyses, higher Time 1 religiosity (a composite of importance of religion and frequency of church attendance) was associated with a lower likelihood of first sexual intercourse between Time 1 and Time 2. However, transition to sexual activity between Time 1 and Time 2 was not significantly related to Time 2 religiosity. Thus, results do not support a bi-directional association; instead, it appears that teens with higher levels of religiosity tend to delay sexual involvement more than those with lower levels of religiosity.
\end{abstract}

\section{Introduction}

Adolescent sexuality represents an area that frequently catches the interest of researchers, policy makers, and health practitioners. This interest stems largely from the potential negative consequences (e.g. pregnancy and sexually transmitted diseases) associated with sexual activity in the teen years (Maynard, 1997; Centers for Disease Control and Prevention, 2000). Because of these potential consequences, scholars have searched for factors associated with delayed sexual initiation. One such factor is religiosity, or religious attitudes and behaviours (Wilcox, Rostosky, Randall, \& Wright, 2001; Rostosky, Wilcox, Wright, \& Randall, in press). Most research on religion 
and sexuality has sought to understand whether, and to what extent, religiosity influences sexual behaviour. This research suggests that religiosity likely delays the onset of sexual intercourse, and may reduce sexual activity thereafter (Wilcox et al., 2001; Rostosky et al., in press). In addition, some scholars suggest that religion may not only impact sexual behaviour, but there may also be a reciprocal influence whereby sexual behaviour affects religiosity (Thornton \& Camburn, 1989; Benda \& Corwyn, 1997; Wilcox et al., 2001). However, few studies have empirically examined this possibility; hence, more research is needed in order to help provide a clearer picture of how religiosity and sexual behaviour are linked (Wilcox et al., 2001). Therefore, the purpose of this study was to extend the existing research on bi-directional associations between religiosity and adolescent sexual behaviour.

One possible avenue by which religion may influence the timing of an adolescent's transition to sexual activity may be by acting as a source of social control (Ellison \& Levin, 1998; Wilcox et al., 2001). According to social control theorists, humans all have an innate drive towards deviance that can be restrained by bonds to social organizations (Durkheim, 1897/1951; Hirschi, 1969). In line with this notion it may be suggested that, although teens might have a tendency towards sexual involvement, if they are bonded to a social organization with conservative norms regarding sexual behaviour (such as a religious organization), they should be motivated to delay sexual behaviour (see Crockett, Bingham, Chopak, \& Vicary, 1996).

Part of the basis for religion as a social control is that it provides consequences for deviance, such as guilt, shame, public embarrassment, and threat or expectation of divine punishment (Ellison \& Levin, 1998). Knowledge and fear of these consequences provides motivation for conformity to religious doctrines. However, if religious individuals do choose to deviate from the norms of their religion, they may experience these consequences and the associated psychological distress. This distress can be thought of as a type of "cognitive dissonance" (Festinger, 1962), a mental state that arises when there is a contradiction between what an individual believes and how he or she behaves. Therefore, if teens affiliated with religions that proscribe premarital sex decide to engage in premarital sexual activity they may experience cognitive dissonance in the form of feelings of "unworthiness." For individuals to decrease the strain of cognitive dissonance, they typically change either the behaviours or cognitions that are in opposition. Hence, a sexually experienced religious teen can reduce cognitive dissonance either by ceasing to engage in sexual activity or by altering religious beliefs or behaviours, so that the belief-behaviour contradiction will decrease. In short, in conjunction with cognitive dissonance theory, social control theories of religion can be used to explain possible bi-directional relations between sexual activity and religiosity.

Our empirical understanding of the association between religiosity and adolescent sexual behaviour is fairly limited. This is likely because the existing research is largely cross-sectional, atheoretical and not directly or specifically focused on religion and sexual behaviour (Wilcox et al., 2001). However, there is enough empirical work to suggest that religiosity is associated with teen sexual behaviour, at least in some contexts and among some populations (Wilcox et al., 2001). Specifically, it seems that higher levels of reported religiosity are linked to later age of initial coitus or less likelihood of reporting sexual experience (for a recent review of this research see Wilcox et al., 2001).

Almost all studies of religiosity and teen sexual behaviour posit a unidirectional linkage whereby religiosity influences sexual behaviour. The key problem with this is that it might por- 
tray an inaccurate picture of relations between religiosity and initial sexual intercourse; it might attribute more influence to religiosity than is warranted. At least part of the association reported between religiosity and first sexual intercourse might be due to the reciprocal influence of transitioning to sexual experience on subsequent religiosity. However, this possibility has not been adequately explored.

Some arguments for reciprocal influences of sexual behaviour on religiosity have emerged, although the research is cross-sectional. For example, one study analysed cross-sectional data using structural equation modelling to test a model of relations between religiosity, sexual attitudes, and sexual behaviours among White teens 18 years of age (Thornton \& Camburn, 1989). Church attendance significantly predicted sexual attitudes (permissiveness) and behaviours (coital experience and number of sex partners), whereas sexual permissiveness but not coital experience predicted religious attendance (Thornton \& Camburn, 1989). Another cross-sectional study, which utilized 2-stage least-squares regression analysis to examine a model of religiosity and several forms of delinquency, reported that religiosity did not significantly predict frequency of sexual intercourse in the past year, but frequency of sexual intercourse negatively predicted religiosity (Benda \& Corwyn, 1997). These studies offer mixed support for bi-directional influences between religiosity and initial coitus, but, given their cross-sectional design, the findings must be seen as tentative. Specifically, in both studies the authors merely examined relations in one direction, and then the other, according to the models they proposed; they did not assess change in religiosity. Thus, no conclusions are possible regarding causal directionality.

A recent study tested bi-directional associations between religiosity and first sexual intercourse over a 1-year period using data from the National Longitudinal Survey of Adolescent Health (Meier, 2003). The sample consisted of 15-18 year old virgins. Higher initial religiosity was linked to lower likelihood of transition to sexual intercourse for female teens but not male teens (after controlling for sex attitudes), but engaging in sexual activity was not associated with a subsequent change in religiosity for male teens or female teens. Hence, this study provides partial support for the influence of religion on sexual activity, but no support for a reciprocal effect of initial sexual experience on religiosity.

In summary, while higher religiosity is often associated with delayed first sexual intercourse or lower likelihood of sexual experience, the few studies that have examined the reciprocal effect of transition to sexual activity on religiosity have yielded mixed results. Moreover, of the three studies that have tested bi-directional relations between religiosity and initial sexual intercourse, only one has been longitudinal. Hence, to advance our understanding of the ways in which teen religiosity is related to sexual behaviour, further investigations of bi-directionality using longitudinal methodology are warranted.

The current study was a 2-year longitudinal study involving data from two different time points. The goal of the study was to examine bi-directional influences between religiosity and teen sexual behaviour using longitudinal data. Based on prior theory and research, two hypotheses were formulated. First, it was hypothesized that teens who reported higher religiosity would be less likely to transition to sexual activity than those who reported lower religiosity. Second, it was hypothesized that teens who transitioned to sexual activity would experience a significant decrease in religiosity. In order for a bi-directional view of the association between religion and teen sexual behaviour to be supported, religiosity must predict the transition to sexual activity, and transition to 
initial intercourse must predict subsequent religiosity. Lastly, prior research on religiosity and teen sexuality has sometimes found that associations differ according to gender and ethnicity. Thus, we also examined gender and ethnicity effects.

\section{Method}

\subsection{Sample and procedures}

Data came from the National Longitudinal Survey of Youth (NLSY). The NLSY began in 1979 with a national sample of young adults aged 14-21 $(N=12,686$; female $N=6,283$; Zagorsky \& White, 1999), with an oversample of Blacks, Hispanics, and low SES Whites; the low SES Whites have since been dropped from the study. In 1986, children of female participants were added to the study, and have been assessed every 2 years thereafter. Since 1988, children 10 years and older have provided self-report data on religiosity, and those 13 years and older have reported on their sexual experience.

The sample for the present study was drawn from the 635 teens aged 15-16 in 1996. These teens were selected because they were administered the relevant religiosity and sexuality questions in both 1996 (Time 1) and 1998 (Time 2). At Time 1 data collection, 252 (40\%) reported prior sexual intercourse, 332 (52\%) reported they had never had sexual intercourse, and 51 (8\%) had missing data on the sexual behaviour variable. Additionally, of the 332 Time 1 virgins, 1 was missing data on Time 1 religiosity, and 28 were missing data on Time 2 sexual intercourse. The present study involved those teens who were virgins in 1996 and had complete data on study variables. Thus, the analytic sample included 303 sexually inexperienced teens (22\% Hispanic, 35\% Black, $43 \%$ non-Hispanic/non-Black; 53\% male). Individuals included in the final analyses $(N=303)$ did not differ significantly from those with missing data $(N=29)$ in terms of gender, ethnicity, religiosity, or sexual behaviour.

\subsection{Measures}

\subsubsection{Ethnicity}

Ethnicity was coded by the NLSY as Hispanic, Black, or non-Hispanic/non-Black. The non-Hispanic/non-Black teens were primarily White, and thus will hereafter be referred to as White teens. For the analyses conducted in the present study, ethnicity was dummy coded into two variables using White teens as the reference or contrast group. Thus, one dummy coded variable compared Hispanic teens to Black teens and White teens, and the other compared Black teens to Hispanic teens and White teens.

\subsubsection{Religiosity}

Teens' perceptions of how important religion was to them were assessed at each time point with the question, "How important would you say religion is to you?," with a response scale from 1 (not important at all) to 4 (very important; Time 1: $M=3.27$; s.D. $=0.86$; Time $2: M=3.30$; s.D. $=0.80)$. Frequency of religious attendance in the past year was assessed at each time point by the question, "In the past year about how often have you attended religious services?," with a response scale from 1 (never) to 6 (once a week or more; Time 1: $M=3.38$; s.D.=1.75; Time 2: $M$ 
$=3.14$; S.D. $=1.68$ ). Due to high correlations between the two religiosity items (Time 1: $r=0.47$; Time $2: r=0.50$ ), religiosity composites were formed for each time point. The religiosity composites were created by first standardizing each item (using z-score transformation) and then averaging individual scores on the two items (Time 1: $M=0.0$; s.D. $=0.86$; Time 2: $M=0.0$; s.D. $=0.87$ ).

\subsubsection{Sexual status}

At each time point, teens answered yes or no to the question, "Have you ever had sexual intercourse?" (no $=0$, yes $=1)$. Using this measure it can be established whether teens had their first sexual experience between the first and second time point $(146 ; 48 \%)$ or whether they were still virgins at the second time point $(N=157 ; 52 \%)$.

\section{Results}

Analyses were conducted using hierarchical logistic regression to test the hypothesis that religiosity negatively predicts subsequent first sexual intercourse, and hierarchical linear regressions to determine whether transition to sexual intercourse negatively predicts subsequent religiosity. Given that prior research suggests there may be gender and ethnic differences in religiosity, sexual behaviour, and the associations between the two (Wilcox et al., 2001), gender and ethnicity were entered on the first step in all analyses. Further, gender and ethnic interactions were assessed by entering interaction terms for gender by religiosity and ethnicity by religiosity as a final step in each analysis.

\subsection{Religiosity predicting first sexual intercourse}

Hierarchical logistic regression analyses were used to test the hypothesis that religiosity at Time 1 would be negatively associated with sexual experience at Time 2 (Hypothesis 1). Gender and ethnicity were entered in the first step, $\chi^{2}(3,303)=3.38$; ns, and religiosity in the second step, $\chi^{2} \Delta(1,303)=6.06 ; p<0.05$ : Time 1 religiosity predicted first sexual intercourse by Time 2 , after controlling for gender and ethnicity (Table 1). Specifically, teens who reported higher Time 1 reli-

Table 1

Hierarchical logistic regression of time 1 religiosity on time 2 sexual status

\begin{tabular}{|c|c|c|c|c|c|c|}
\hline \multirow[t]{2}{*}{ Predictors } & \multicolumn{3}{|l|}{ Step 1} & \multicolumn{3}{|l|}{ Step 2} \\
\hline & $B$ & Wald $\chi^{2}$ & Odds & $B$ & Wald $\chi^{2}$ & Odds \\
\hline Gender & -0.17 & 0.52 & 0.85 & -0.07 & 0.08 & 0.94 \\
\hline Hispanic & 0.45 & 2.23 & 1.57 & 0.49 & 2.55 & 1.63 \\
\hline Black & 0.38 & 2.04 & 1.46 & 0.53 & 3.65 & 1.70 \\
\hline Time 1 religiosity & & & & $-0.35^{*}$ & 5.90 & 0.70 \\
\hline
\end{tabular}

Note: sexual status $(0=$ no; $1=$ yes $)$; gender $(0=$ male, $1=$ female $)$; Hispanic $(0=$ other, $1=$ Hispanic $)$; Black $(0=$ other; $1=$ Black).

$N=303$.

$* p<0.05$ 
giosity were less likely to report sexual experience at Time 2 than those who reported lower religiosity. In the third step, interaction terms were entered for ethnicity by Time 1 religiosity and gender by Time 1 religiosity. None of the interaction terms was significant, and the step did not account for a significant amount of variance; hence, it was not included in the final model. Thus, relations between Time 1 religiosity and Time 2 sexual status did not differ significantly by gender or ethnicity. Although the second step of the model was significant, due to the low contribution of gender and ethnicity the final model accounted for a non-significant amount of variance, $\chi^{2}(4,303)$ $=9.44 ; p<0.10$.

\subsection{Sexual experience predicting subsequent religiosity}

To examine the hypothesis that transition to sexual activity would be negatively associated with Time 2 religiosity (Hypothesis 2), linear regression analyses were utilized to predict Time 2 religiosity from transition to sex, controlling for gender, ethnicity, and initial levels of religiosity. Gender, ethnicity, and Time 1 religiosity were entered on the first step, $F(4,298)=43.63 ; p<0.001$; and first sexual intercourse was entered on the second step, $F(1,297)=0.86$; ns. Transition to sexual activity between Time 1 and Time 2 did not significantly predict later religiosity (Table 2). Interaction terms for gender by Time 2 sexual status and ethnicity by Time 2 sexual status were entered in step three. There were no significant gender and ethnic interactions, and the step did not significantly increase the amount of variance accounted for; thus, this step was omitted from the final model. Largely due to the addition of prior religiosity $(b=0: 57$; po0:001), the final model accounted for a significant amount of variance, $F(5,297)=35.06 ; p<.001$.

\section{Discussion}

In this 2-year longitudinal analysis, bi-directional linkages between religiosity and first sexual intercourse were examined using a sample of 15-16 year old virgins at Time 1. The longitudinal nature of this study, and the large, ethnically diverse sample provided an excellent opportunity

Table 2

Hierarchical regression of time 2 sexual status on time 2 religiosity

\begin{tabular}{|c|c|c|c|c|c|c|}
\hline \multirow[t]{2}{*}{ Predictors } & \multicolumn{3}{|c|}{ Step 1} & \multicolumn{3}{|l|}{ Step 2} \\
\hline & $B$ & SE & Beta & $B$ & SE & Beta \\
\hline Gender & 0.04 & 0.08 & 0.02 & 0.04 & 0.08 & 0.02 \\
\hline Hispanic & 0.06 & 0.10 & 0.03 & 0.07 & 0.11 & 0.03 \\
\hline Black & 0.18 & 0.09 & 0.10 & 0.19 & 0.09 & 0.10 \\
\hline Time 1 religiosity & $0.58^{*}$ & 0.05 & $0.58^{*}$ & $0.58^{*}$ & 0.05 & $0.57^{*}$ \\
\hline Time 2 sexual status & & & & -0.07 & 0.08 & -0.04 \\
\hline
\end{tabular}

Note: sexual status $(0=$ no; $1=$ yes $)$; gender $(0=$ male, $1=$ female $)$; Hispanic $(0=$ other, $1=$ Hispanic $)$; Black $(0=$ other; $1=$ Black).

$N=303$.

${ }^{*} p<0.05$. 
to add to the limited literature on bi-directionality between teen religiosity and sexuality. Results yielded support for the hypothesis that religiosity may help delay first sexual intercourse, and this effect did not differ according to gender or ethnicity. Specifically, higher religiosity at 15-16 years was significantly associated with still being a virgin 2 years later. On the other hand, the hypothesis that becoming sexually active might influence subsequent religiosity was not supported.

The finding that religiosity was associated with postponed first sexual intercourse is consistent with prior research. Of the existing studies that have utilized similar measures of religiosity, most have found higher religiosity to be related to delayed first sexual intercourse or lower likelihood of sexual experience (Cvetkovich \& Grote, 1980; Thornton \& Camburn, 1989; Neumark-Sztainer, Story, French, \& Resnick, 1997; Perkins, Luster, Villarruel, \& Small, 1998; Bearman \& Brückner, 2001; Meier, 2003). Given that many of these past studies have been cross-sectional, the current longitudinal results bolster the notion that religiosity can act as a "protective factor" against teen sexual intercourse.

Contrary to expectations, there was no evidence of a reciprocal effect of first sexual intercourse on subsequent religiosity. That is, teens who had their first sexual intercourse between the two study time points did not show a significant reduction in religiosity, although such a reduction was predicted based on (cognitive dissonance and social control) theories and past cross-sectional findings. Two prior studies have reported results that suggest teen sexuality might affect subsequent levels of religiosity (Thornton \& Camburn, 1989; Benda \& Corwyn, 1997). However, both were cross-sectional, limiting their ability to discern temporal ordering. A recent longitudinal study, on the other hand, found no support for teen sexuality influencing religiosity (Meier, 2003). Similar to Meier's (2003) analysis, the present study controlled for prior religiosity and prior sexual behaviour, thus allowing for better examination of temporal order. Both studies found that transition to sexuality, when controlling for prior sexual behaviour and religiosity, does not predict a change in religiosity. Thus, differences in research methodology may at least partially account for differences in findings.

There are several limitations to this study that provide opportunities for future research. First, although the study was longitudinal, causality cannot be firmly established. For example, religiosity might not lead teens to postpone sexual intercourse; rather, some third variable, such as temperamental differences related to risk-preference, may be responsible for both high importance placed on religion and delayed first sexual intercourse (Miller \& Hoffman, 1995; Kowaleski-Jones $\&$ Mott, 1998). Future studies should include variables such as these in order to help rule out alternative explanations for the religion-sexual behaviour association. Second, this study involved only two time points, 2 years apart. A longitudinal study with two time points is better than a cross-sectional one, but causal ordering of events (i.e. changes in religious and sexual behaviour) can be better assessed the more time points that are included, and the closer they are together. It is possible that fairly dramatic changes in behaviours and attitudes can occur over a 2-year period, and these changes may be better identified if multiple, frequent measurements are taken. Third, this study only involved a two-item composite measure of religiosity. Given that religiosity is a fairly complex phenomenon, utilization of more sophisticated measures (such as Gorsuch \& McPherson's (1989) measure of intrinsic/extrinsic religiosity) may lead to clearer results. Lastly, the analytic sample was limited to teens who were virgins at the initial time point, leading to the exclusion of $40 \%$ of the original sample of $15-16$ year olds. Although this allowed for the control of pri- 
or sexual experience, it resulted in a sample that is likely less representative of adolescents nationwide, and does not provide information about linkages between religiosity and sexuality among teens who begin having sex during early adolescence.

Despite these limitations, the current findings add to a growing literature suggesting that religiosity is associated with delayed sexual involvement. Future research should focus on elucidating the mechanisms that underlie this association in order to clarify the processes that link religiosity and sexuality. It is conceivable that once these mechanisms become clearer, information will be available for the development of interventions from a variety of perspectives (e.g. programs to help teens postpone sexual activity and reduce sexual risk-taking), including programs that are not religion-based. For example, some research suggests that religion might influence sexual behaviour by affecting attitudes towards sex, such that teens with more conservative sexual attitudes engage in lower levels of sexual risk-taking (Meier, 2003). Although an intervention to promote religiosity among teens would undoubtedly be controversial, attempts to change attitudes and beliefs regarding sexuality (e.g. promoting individual and group norms that discourage early sexual involvement) are typically accepted (for a review, see Kirby, 2001). As scholars uncover more of the intricacies of the religion-sex association, they will gain more of an understanding of how, why, and in what situations religiosity and sexuality are related. A clearer picture of the relations between adolescent religiosity and sexual behaviour has the potential to provide valuable insight into how to promote responsible and healthy sexuality among all teenagers.

\section{Acknowledgements}

The authors thank Lisa Crockett and Brian Wilcox for their comments on several earlier drafts. The authors also appreciate the statistical and methodological consultation offered by Calvin Garbin. This research was funded by a grant to M. Raffaelli and L. J. Crockett from the National Institutes of Mental Health (1-RO1-MH62977-02).

\section{References}

Bearman, P. S., \& Brückner, H. (2001). Promising the future: Virginity pledges and the transition to first intercourse. American Journal of Sociology, 106, 859-912.

Benda, B. B., \& Corwyn, R. F. (1997). A test of a model with reciprocal effects between religiosity and various forms of delinquency using 2-stage least-squares regression. Journal of Social Services Research, 22, 2752.

Centers for Disease Control and Prevention (2000). Tracking the hidden epidemics: Trends in STD's in the United States. Washington, DC.

Crockett, L. J., Bingham, C. R., Chopak, J. S., \& Vicary, J. R. (1996). Timing of first sexual intercourse: The role of social control, social learning, and problem behavior. Journal of Youth and Adolescence, 25, 89111.

Cvetkovich, G., \& Grote, C. (1980). Psychosocial development and the social problem of teenage illegitimacy. In C. Chilman (Ed.), Adolescent pregnancy and childbearing (pp. 15-41). Washington, DC: US Government Printing Office.

Durkheim, E. (1951). Suicide. New York: The Free Press (Original work published in 1897). 
Ellison, C. G., \& Levin, J. S. (1998). The religion-health connection: Evidence, theory, and future directions. Health Education and Behavior, 25, 700-720.

Festinger, L. (1962). A theory of cognitive dissonance. Stanford, CA: Stanford University Press.

Gorsuch, R. L., \& McPherson, S. E. (1989). Intrinsic/extrinsic measurement: I/E-revised and single-item scales. Journal for the Scientific Study of Religion, 18, 348-354.

Hirschi, T. (1969). Causes of delinquency. Berkeley: University of California Press.

Kirby, D. (2001). Emerging answers: Research findings on programs to reduce teen pregnancy. Washington, DC: National Campaign to Prevent Teen Pregnancy.

Kowaleski-Jones, L., \& Mott, F. L. (1998). Sex, contraception and childbearing among high-risk youth: Do different factors influence males and females? Family Planning Perspectives, 30, 256-262.

Maynard, R. A. (Ed.), (1997). Kids having kids: Economic costs and social consequences of teen pregnancy. Washington, DC: The Urban Institute Press.

Meier, A. M. (2003). Adolescents' transition to first intercourse, religiosity, and attitudes about sex. Social Forces, 81, 1031-1052.

Miller, A. S., \& Hoffman, J. P. (1995). Risk and religion: An explanation of gender differences in religiosity. Journal for the Scientific Study of Religion, 34, 63-75.

Neumark-Sztainer, D., Story, M., French, S., \& Resnick, M. D. (1997). Psychosocial correlates of health compromising behaviors among adolescents. Health Education Research, 12, 37-52.

Perkins, D. F., Luster, T., Villarruel, F. A., \& Small, S. (1998). An ecological, risk-factor examination of adolescents' sexual activity in three ethnic groups. Journal of Marriage and the Family, 60, 660-673.

Rostosky, S. S., Wilcox, B. L., Wright, M. L. C., \& Randall, B. A. (in press). The impact of religiosity on adolescent sexual behavior: A review of the evidence. Journal of Adolescent Research, in press.

Thornton, A., \& Camburn, D. (1989). Religious participation and adolescent sexual behaviors and attitudes. Journal of Marriage and the Family, 51, 641-653.

Wilcox, B. L., Rostosky, S. S., Randall, B., \& Wright, M. L. C. (2001). Reasons for hope: A review of research on adolescent religiosity and sexual behavior. In B. D. Whitehead, B. L. Wilcox, \& S. S. Rostosky (Eds.), Keeping the faith: The role of religion and faith communities in preventing teen pregnancy (pp. 31-82). Washington, DC: The National Campaign to Prevent Teen Pregnancy.

Zagorsky, J. L., \& White, L. (1999). NLSY79 user's guide: a guide to the 1979-1998 national longitudinal survey of youth data. Washington, DC: US Department of Labor. 